\title{
Behavior of RC beams strengthened in shear with ultra-high performance fiber reinforced concrete (UHPFRC)
}

\author{
Mohammed A. Sakr ${ }^{1,}$, Ayman A. Sleemah ${ }^{1}$, Tarek M. Khalifa ${ }^{1}$, Walid N. Mansour ${ }^{2}$ \\ ${ }^{1}$ Department of Structural Engineering, Tanta University, Tanta, Egypt \\ ${ }^{2}$ Department of Civil Engineering, Kafrelsheikh University, Kafrelsheikh, Egypt
}

\begin{abstract}
This paper investigates the behavior of RC beams strengthened in shear with UHPFRC. In order to ensure high quality and facilitate the strengthening process on site applications, it has been considered to apply UHPFRC as a plate pasted on concrete using epoxy. In addition to the control beam, two strengthened RC beams using prefabricated UHPFRC plates were prepared and tested. All beams had the same rectangular cross-section geometry $(150 \mathrm{~mm} \times 300 \mathrm{~mm} \times 2000 \mathrm{~mm})$. Two different techniques were considered during the strengthening process; the first application was the addition of two $30 \mathrm{~mm}$ UHPFRC plates, whereas the second beam strengthened using one $60 \mathrm{~mm}$ UHPFRC plate. Results showed that strengthening RC beams using two UHPFRC plates improved load carrying capacity with $145 \%$ comparing with the control beam. Moreover UHPFRC plate in case of strengthening one side of the RC beam prevented shear cracks from appearing on the strengthened side.
\end{abstract}

\section{Introduction}

Several techniques have been used for the strengthening of RC structures. Drawbacks of existing techniques make the need to develop a new material is necessary. Recently, UHPFRC used for both repair and strengthening of RC structures. Yoo et al. [1] investigated the effect of fiber content on the material and interfacial bond properties of UHPFRC. Results showed that $3 \%$ steel fiber by volume yielded the best performance in terms of compressive strength, elastic modulus, shrinkage behavior, and interfacial bond strength. Additionally, it was shown that fracture parameters including cohesive stress and fracture energy are significantly influenced by the fiber content: higher cohesive stress and fracture energy were achieved with higher fiber content.

The importance of fiber distribution was highlighted by [2]. Slabs with the same sizes but different flowing directions were cast. Experimental results indicated that the orientation of fibers affected the performance of the material. Hence, the optimum performance was achieved from the specimens with axis parallel to fiber orientation. Moreover, considerable attention has been paid to strengthen RC structures using UHPFRC layers or jackets, [3-10] presented real applications of UHPFRC for the rehabilitation of crash barrier wall of highway bridge, bridge pier, and industrial floors, and the efficiency of this method for cast in-situ and prefabrication, using standard equipment for concrete manufacturing, was highlighted.

\footnotetext{
*Corresponding author: mhsakr010@yahoo.com
}

Al-Osta et al. [3] investigated, the effectiveness and efficiency of two different techniques for strengthening of RC beams using UHPFRC i.e.; (i) by sand blasting $\mathrm{RC}$ beams surfaces and casting UHPFRC in-situ around the beams inside a mold and (ii) by bonding prefabricated UHPFRC strips to the RC beams using epoxy adhesive. Beams under each technique were strengthened in three different strengthening configurations; (i) bottom side strengthening (ii) two longitudinal sides strengthening (iii) three sides strengthening. Test results showed that beams strengthened on three sides showed the highest capacity enhancement, while beams strengthened only at the bottom side showed the least enhancement. Finite element (FE) and analytical models were developed to predict the behavior of the beam specimens. The result of the models showed good agreement with experimental results, as they were able to predict the behavior of the beams with high accuracy.

Tanarslan et al. [10] presented the results of a threestep experimental program. In the first step, material tests were conducted to determine the mix proportions of UHPFRC that can be used for strengthening RC beams when applied as a full scaled laminate. In the second step, real sized laminates were tested to define the bare properties of full-scaled laminates. In the final step, flexurally deficient RC beams were strengthened with 30 $\mathrm{mm}$ thick UHPFRC laminates using two different bonding methods: gluing with epoxy and mechanical anchoring. In addition, longitudinal reinforcing bars were added into the laminates and their effectiveness was evaluated to improve the success of the applied methods. The results showed that UHPFRC laminate 
usage, especially in the case of anchorage, is an effective technique to improve the load carrying capacity of RC beams. Moreover, it was observed that adding reinforcing bars into the laminates could improve the efficiency of the applied method remarkably.

In spite of prior valuable studies on using UHPFRC in strengthening of RC beams, very few publications are found in the literature that discuss shear strengthening of RC beams. Also, to the authors' best knowledge none of these researches consider the individual contribution of longitudinal side strengthening on the shear strength of $\mathrm{RC}$ beams. This paper presents an experimental program discuss shear strengthening of RC beams using prefabricated UHPFRC plates which rarely studied in literature. Trial mixtures were prepared and tested firstly to select the optimum mixture design before the application of the UHPFRC plates for the strengthening preocess of RC beams.

\section{Experimental Setup}

Before the application of the UHPFRC plates for the strengthening of $\mathrm{RC}$ beams, it is of high importance to capture its mechanical properties which are required for the application in this field.

\subsection{Investigation of different mixture designs}

For the application of UHPFRC material for the strengthening of $\mathrm{RC}$ beams high mechanical properties are required. A preliminary study has been conducted on the investigation of the properties of different mixture designs of UHPFRC. The mixture with the optimum performance has been adopted for the next investigations and the application of the material for the strengthening of RC beams.

For the preparation of UHPFRC, and in order to improve the homogeneity and the density of the material, only materials with fine particles are used. Therefore, in the present study, sand with a maximum particle size of $500 \mu \mathrm{m}$ was used, together with dry silica fume, fly ash, quartz and cement. A low water/cement ratio was also used together with Sika viscocrete superplasticizer (S.P) in order to secure the workability of the mixture. Additionally, 2\% per volume end-hooked steel fibers were incorporated into the mixture. The steel fibers had a length of $30 \mathrm{~mm}$ and a diameter of $0.80 \mathrm{~mm}$; the tensile strength was $1000 \mathrm{MPa}$, while the modulus of elasticity was $200 \mathrm{GPa}$.

Finally, portland cement $42.5 \mathrm{R}$ type I was used for the preparation of the all the examined mixtures.

For the preparation of the different mixture designs, different quantities of cement, quartz, fly ash and silica fume were incorporated into the mixture. The rheological properties of the UHPFRC are of high importance for the application of the material for the strengthening of RC beams. The large volumes of fibers in the mixture make the compaction of the material difficult using conventional methods. All the examined mixture designs are presented in Table 1.

For the mixing of the materials, all the dry ingredients were mixed first for four minutes. Then, water and superplasticizer were added into the mixture. Once the mixture reached the wet stage, steel fibers were added. The specimens were demolded forty-eight hours after casting and placed in a water tank for twenty-six days. The specimens were tested twenty-eight days after casting. This is a time frame over which the cementitious materials develop strength close to the maximum that they can reach. The preparation of the specimens is presented in Fig. 1.

UHPFRC cylinders specimens have $50 \mathrm{~mm}$ diameter and $100 \mathrm{~mm}$ length were prepared for the indirect tensile (Brazilian) test, setup is depicted in Fig. 2a. The flexural tests were conducted using 40x40x160 $\mathrm{mm}^{3}$ UHPFRC prisms, followed by compression tests using 40x40x 80 $\mathrm{mm}^{3}$ UHPFRC prisms. The experimental setup for these tests is presented in Fig. 2b. Three prisms and three cylinders were used for each investigation and a universal testing machine of $300 \mathrm{kN}$ total capacity was used.

Table 1. Examined mixture designs

\begin{tabular}{|c|c|c|c|c|c|c|c|c|}
\hline 离 & 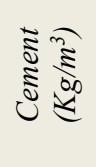 & 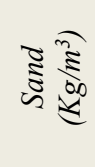 & 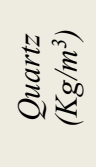 & 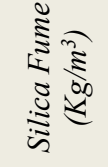 & 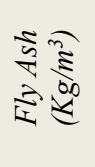 & 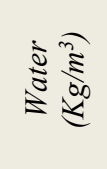 & 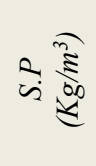 & 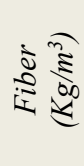 \\
\hline M1 & 850 & 850 & 340 & 212.5 & - & 178.5 & 42.5 & 157 \\
\hline M2 & 850 & 850 & 340 & 127.5 & 85 & 178.5 & 42.5 & 157 \\
\hline M3 & 920 & 1005 & - & 225 & - & 172 & 41.2 & 157 \\
\hline M4 & 928 & 877 & 77 & 222 & - & 195 & 40 & 157 \\
\hline
\end{tabular}




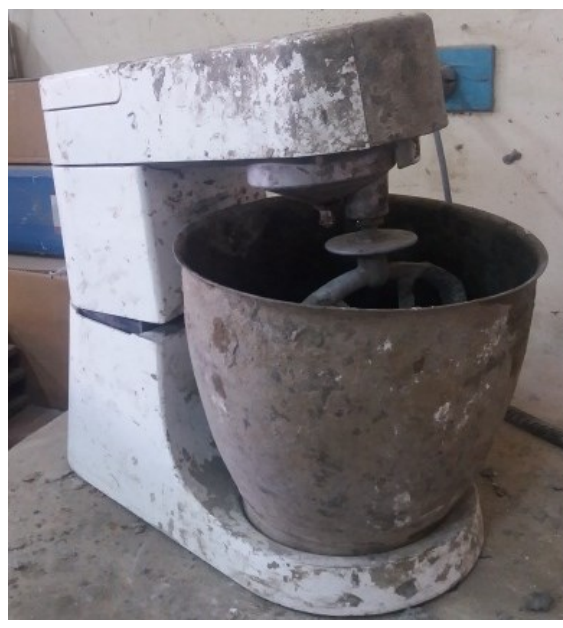

(a)

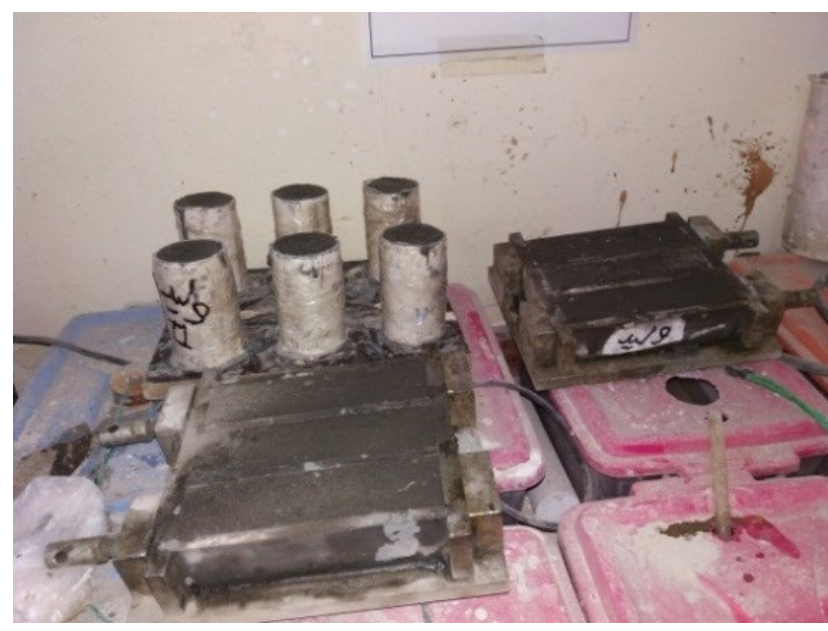

(b)

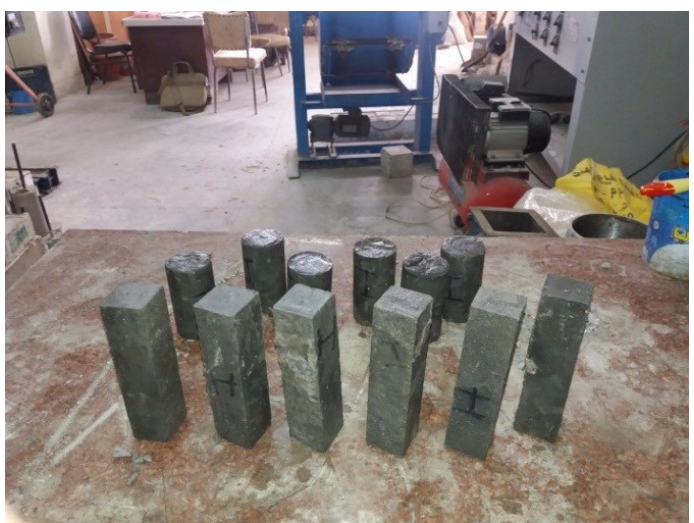

(c)

Fig. 1. Preparation of the specimens: a) mixer used for mixing the materials b) cylinder and cube specimens after casting c) cylinder and cube specimens after demolding

The results of the indirect tensile tests, flexural and compression tests of mixtures M1, M2, M3 and M4 are presented in Table 2. As shown in the same table, mixture M1 has the largest compression strength,

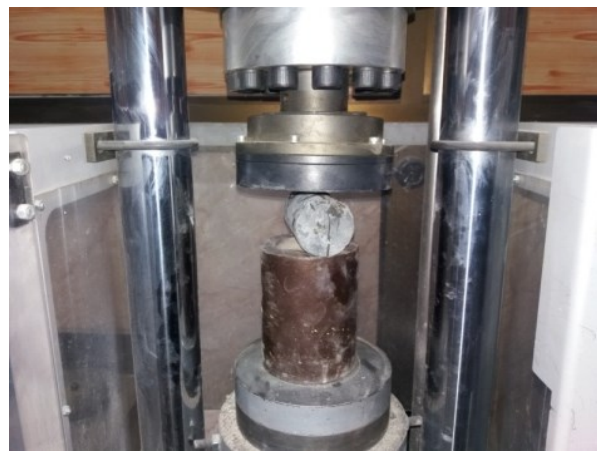

(a) flexural strength and tensile strength. Consequently, mixture M1 considered the optimum mixture which will be used for the strengthening process of RC beams.

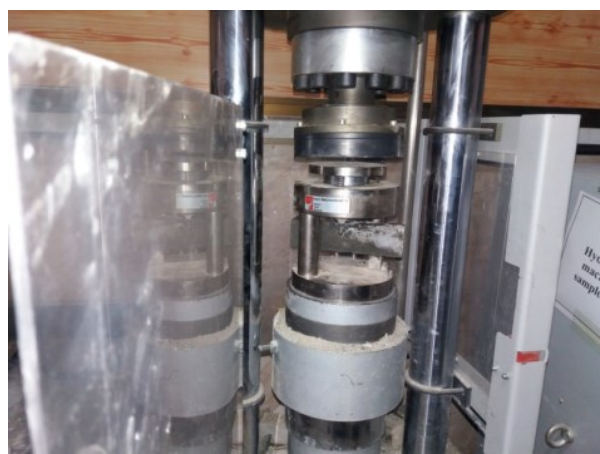

(b)

Fig. 2. Experimental setup for: a) indirect tensile test, b) flexural and compression tests 
Table 2. Experimental results for the different mixture design

\begin{tabular}{cccc}
\hline \hline Mixture & $\begin{array}{c}\text { Mean } \\
\text { compression } \\
\text { strength(MPa) }\end{array}$ & $\begin{array}{c}\text { Mean Tensile } \\
\text { strength, } f_{c t}(M P a)\end{array}$ & $\begin{array}{c}\text { Mean Flexural } \\
\text { strength(MPa) }\end{array}$ \\
\hline M1 & 135.37 & 11.36 & 24.08 \\
M2 & 88.65 & 9.76 & 18.15 \\
M3 & 83.20 & 8.93 & 16.28 \\
M4 & 97.00 & 10.91 & 21.23 \\
\hline \hline
\end{tabular}

\subsection{Strengthening of RC beams with prefabricated UHPFRC plates}

In the present investigation a realistic application of the UHPFRC plates for the strengthening of RC beams has been conducted and beams with dimensions similar to those which can be found in real structures have been constructed. The geometry and the reinforcement of the proposed RC beams are presented in Fig. 3 .

The RC beams were reinforced with only four stirrups with a diameter of $8 \mathrm{~mm}$ in order to represent weak beams fail in shear. Additionally, two longitudinal ribbed steel bars with a diameter of $18 \mathrm{~mm}$ and length of $1950 \mathrm{~mm}$ were placed at the tensile side of each beam. On the contrary, two longitudinal ribbed steel bars with a diameter of $10 \mathrm{~mm}$ and length of $1950 \mathrm{~mm}$ were placed at the compressive side of each beam. The examined techniques set as a target the shear strengthening of beams. Finally, plastic cubes were used in order to ensure the required concrete cover of the reinforcement, which was equal to $25 \mathrm{~mm}$. The yield strength of steel reinforcement considered to be $400 \mathrm{MPa}$, whereas the concrete compressive strength was found to be $30 \mathrm{MPa}$. Once the reinforcement and the molds were ready, the concrete mixture was casted. The mixture design used in the present study was designed and transmitted by DELTAMIX for ready mix concrete.

The RC beam specimens were tested under a four point loading arrangement as illustrated in Fig. 4. As can be seen, the span length was equal to $1600 \mathrm{~mm}$ while the distance between the two loading points was equal to $550 \mathrm{~mm}$. Linear variable differential transducers (LVDTs) were used to measure displacement at midspan.

The experimental results for the load deflection curves of the RC beams are presented in Fig. 5. Beams $\mathrm{C}-\mathrm{S}$ showed the typical behavior of an ordinary RC member with insufficient shear steel, failed in a brittle manner with low energy absorption before failure. The maximum load of the C-S beam was $115 \mathrm{kN}$. Additionally, the deflection at the maximum load was found to be equal to $5.35 \mathrm{~mm}$. Moreover, from Fig. 5, it can be noticed that once the control beam reached its maximum load carrying capacity, the load dropped rapidly. The cracking patterns consist of a pure diagonal shear crack in the constant shear spans.

Based on the experimental results it is concluded that the strengthening process has significantly improved the structural behavior of the RC beams fail in shear. The maximum load of beam ST-1S was found to be equal to $153 \mathrm{kN}$, and from the linear part of the load-deflection curve, the stiffness was calculated to be equal to 23.8 $\mathrm{kN} / \mathrm{mm}$. Moreover, the deflection at the maximum load was equal to $7.25 \mathrm{~mm}$, while at the failure was equal to $10 \mathrm{~mm}$. The first crack during the testing appeared for a value of load equal to $60 \mathrm{kN}$ on the UHPFRC plate. During the testing, more flexural cracks appeared along the strengthened side of the RC beam while shear cracks, appeared along the non-strengthened side. The maximum load of beam ST-1S is $34 \%$ only higher than control beam C-S. This small ratio refer to debonding failure occurred for the UHPFRC plate due to cracking of the concrete underneath the UHPFRC plate.

Strengthening RC beam using two UHPFRC plates, beam ST-2S, improved the maximum load capacity to reach $281 \mathrm{kN}, 145 \%$ higher than control beam C-S. Additionally, the deflection at the maximum load was equal to $8.23 \mathrm{~mm}$. As the beam reached its maximum load carrying capacity a failure at the UHPFRC plates began. The maximum load dropped suddenly due to UHPFRC plates rupture. The first crack during the testing appeared for a value of load equal to $93 \mathrm{kN}$ on the UHPFRC plate. 
(a)
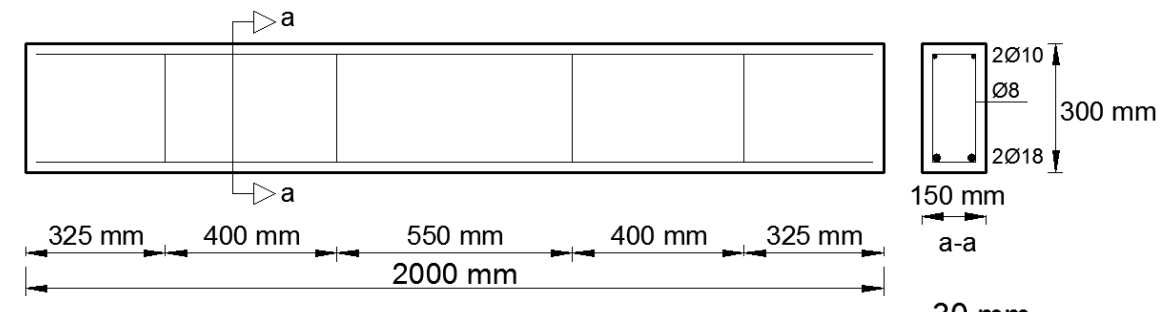

$150 \mathrm{~mm}$

$\mathrm{a}-\mathrm{a}$

$\rightarrow a$

$30 \mathrm{~mm}$

(b)

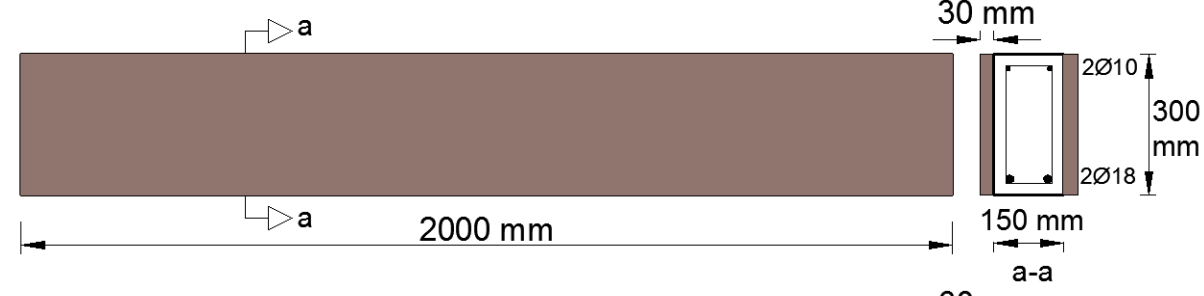

(c)

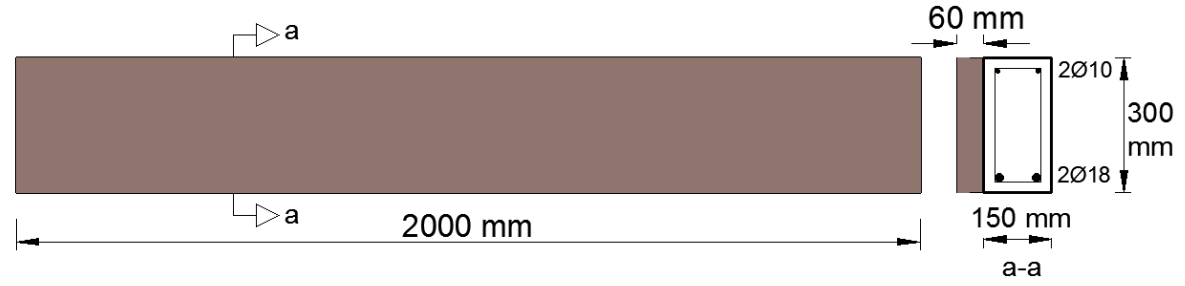

Fig. 3. Strengthening configuration: a) beam C-S, b) beam ST-2S, c) beam ST-1S

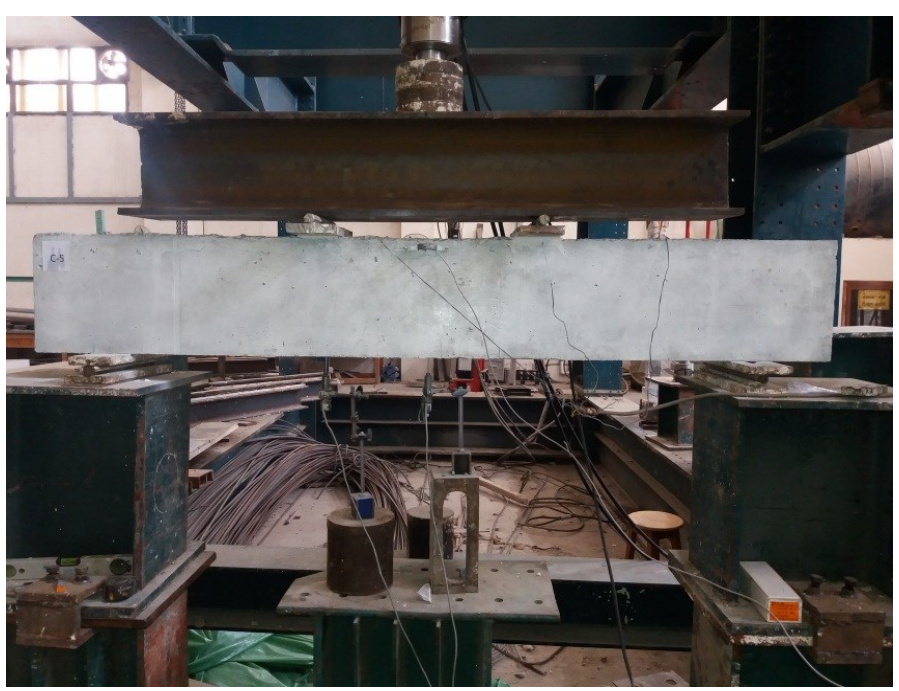

Fig. 4. Test setup 


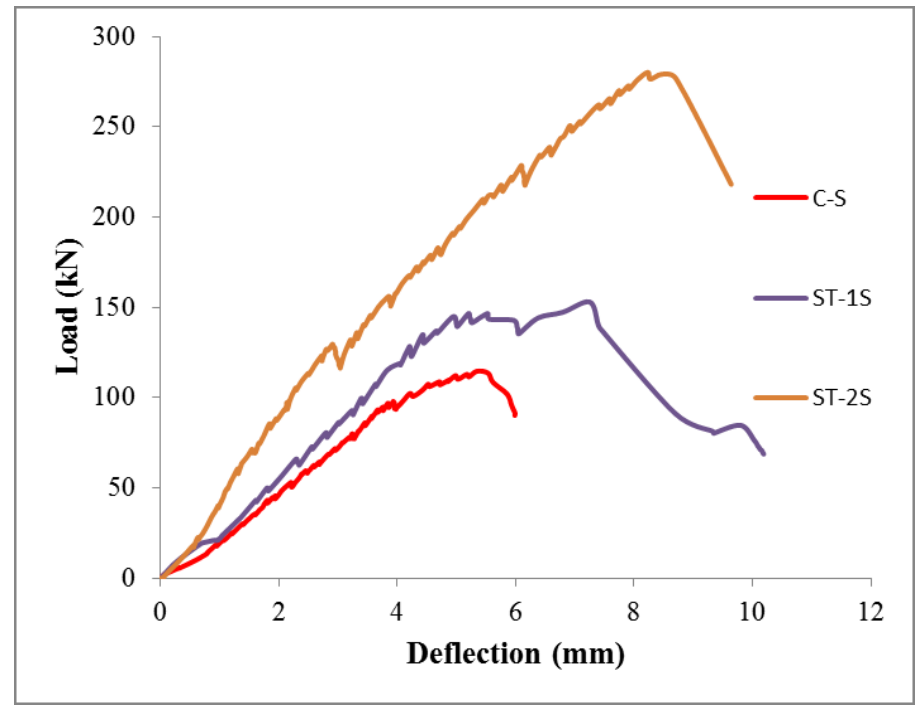

Fig. 5. Load-deflection curves for RC beams

\section{Conclusions}

The experimental program invetigated in the current research reveal the effeciency of using UHPFRC plates for shear strengthening of RC beams. Previous tests were conducted to select the optimum mixture design to produce UHPFRC plates. Mixture M1 has the largest compression strength, flexural strength and tensile strength. Consequently, mixture M1 considered the optimum mixture. Strengthening RC beams using $60 \mathrm{~mm}$ individual UHPFRC plate increased the maximum load capacity $34 \%$ comparing with the control beam, this ratio improved to reach $145 \%$ in case of using two 30 $\mathrm{mm}$ UHPFRC plates. UHPFRC plates was able to prevent the diagonal shear crack from appearing on the strengthened surface, which was obvious on the nonstrengthened surface.

\section{References}

[1] D. Yoo, H. Shin, J. Yang, Y. Yoon, Material and bond properties of ultra high performance fiber reinforced concrete with micro steel fibers, Composites: Part B 58: 122-133 (2014).

[2] L. Ferrara, N. Ozyurt, M. Di Prisco, High mechanical performance of Fiber Reinforced Cementitious Composites: the role of casting-flow induced fiber orientation, Materials and Structures 44: 109-128 (2011).

[3] M.A. Al-Osta, M.N. Isa, M.H. Baluch, M.K. Rahman, Flexural behavior of reinforced concrete beams strengthened with ultra-high performance fiber reinforced concrete, Construction and Building Materials 134: 279-296 (2017).

[4] E. Brühwiler, E. Denarie, Rehabilitation of concrete structures using ultra-high performance fibre reinforced concrete, In: The second international symposium on ultra high performance concrete, Kassel, Germany, 5-7 March. (2008)
[5] E. Brühwiler, Rehabilitation and strengthening of concrete structures using ultra-high performance fibre reinforced concrete. Concrete Repair, Rehabilitation and Retrofitting III, Cape Town, South Africa, 3-5 September. (2012)

[6] I. Iskhakov, Y. Ribakov, K. Holschemacher, T. Mueller, High-performance repairing of reinforced concrete structures, Materials and Design 44: 216222 (2013).

[7] A.P. Lampropoulos, S.A. Paschalis, O.T. Tsioulou, S.E. Dritsos, Strengthening of reinforced concrete beams using ultra-high performance fiber reinforced concrete (UHPFRC), Engineering Structures, 106: 370-384 (2016).

[8] A. Magri, M. Colombo, M. di Prisco, TRM and UHPFRC: retrofitting solutions for structural elements. Concrete Repair, Rehabilitation and Retrofitting III, Cape Town, South Africa, 3-5 September (2012).

[9] M. Safdar, T. Matsumoto, K. Kakuma, Flexural behavior of reinforced concrete beams repaired with ultra-high performance fiber reinforced concrete (UHPFRC), Composite Structures 157: 448-460 (2016).

[10] H.M. Tanarslan, N. Alver, R. Jahangiri, Ç. Yalçınkaya, H. Yazıcı, Flexural strengthening of RC beams using UHPFRC laminates: Bonding techniques and rebar addition, Construction and Building Materials 155: 45-55 (2017). 